\title{
¿PROLETARIADO SIN CABEZA O CUERPO SOCIAL DOMESTICADO? NOTAS PARA UNA LECTURA CRÍTICA DEL ENSAYO DE JOSÉ REVUELTAS
}

\author{
Jaime Ortega ${ }^{1}$
}

\section{Resumen/Abstract:}

El presente texto es una aproximación crítica al Ensayo sobre un proletariado sin cabeza de José Revueltas. A partir de las indicaciones metodológicas heredadas por Louis Althusser en su tratamiento de El Capital y de las nociones de posición idealista y posición materialista, se reconstruye el contenido del Ensayo. En el interior de este, se denota la coexistencia de estas dos posiciones: la idealista que remite a una filosofía de la historia y la materialista, que aborda los problemas específicos de una coyuntura. Finalmente, se apuntala una lectura crítica, en donde la noción de "proletariado de cabeza" debe ser repensada en el conjunto de la historia del movimiento obrero en México y de su relación con el Estado. Las breves conclusiones sólo son pie para pensar el entramado en el que se juega la historia del marxismo.

Palabras clave: Revueltas, proletariado, idealismo, materialismo, El Capital

\section{PROLETARIATE WITHOUT HEAD OR DOMESTICATED SOCIAL BODY? NOTES FOR A CRITICAL READING OF ESSAY DE JOSÉ REVUELTAS}

This text is a critical approach to José Revuelta's Essay on a headless proletariat. From the methodological indications inherited from Louis Althusser in his treatment of Das Kapital and the notions of idealist and materialist position, this paper reconstructs the content of the Essay. In his interior, the coexistence of these two positions is denoted: the idealist that refers to a philosophy of history and the materialistic one, which addresses the specific problems of a conjuncture. Finally, underpinned in his critical reading, the notion of "head of the proletariat" rethink the history of the labour movement in Mexico and its relationship with the State. The brief conclusions are only foot to think about the framework, which played the history of Marxism.

Keywords: Revueltas, proletariat, idealism, materialism, The Capital

\footnotetext{
${ }^{1}$ Universidad Autónoma Metropolitana, México. E-mail: Jaime_ortega83@hotmail.com
} 


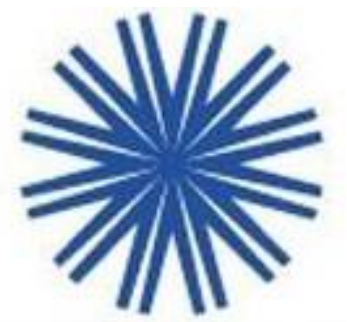

José Revueltas es una figura emblemática tanto de las tradiciones asociadas a opciones políticas de la izquierda como del marxismo entendido este como camino de reflexión de la vida social. Varios motivos convocan a afirmar que es quizá el más importante de los militantes que hicieron parte de la construcción de un discurso crítico durante la primera mitad del siglo XX e impactaron poderosamente en la segunda, especialmente tras su participación en el movimiento estudiantil-popular de 1968. Es posible, además, insistir en el dato bien conocido de su abnegada militancia comunista juvenil, que lo llevó en reiteradas ocasiones a conocer las prisiones del régimen "posrevolucionario" y dejar constancia tanto de los "muros de agua" como del "apando estatal" (Kraniauskas, 2016).

Sin embargo, a la consideración de su militancia es preciso ponderar su paso por diversas corrientes además del comunismo histórico, como lo es su acercamiento a la escisión del Partido Comunista Mexicano, el denominado Partido Obrero Campesino de México (POCM), sus devaneos iniciales con el maoísmo, además del dato nada irrelevante de su larga trayectoria a la sombra de Vicente Lombardo Toledano (durante los años cincuenta, cruciales en su producción literaria) o bien, en el último tramo de su vida el acercamiento innegable con el trotskismo y el consejismo. La insistencia en su vínculo con estas trayectorias ideológicas al interior tanto del comunismo como del marxismo, es lo que permite entender algunas de las obsesiones y búsquedas más intensas que animaron su vida intelectual.

Más allá de su colocación ideológica, es cierto que en la memoria contemporánea se le asocia con la figura del intelectual comprometido, sobre todo tras el crucial año de 1968, que determinó en gran medida su presencia tan intensa en la memoria de quienes adoptaron la seña de identidad de la izquierda en las décadas siguientes. Por último, es preciso recordar que Revueltas fue el último - ¿quizá el único en la segunda mitad del siglo XX? - de los teóricos marxistas que nunca desempeñó papel en la cátedra universitaria, sino que ocupó los lugares claves del intelectual de otra época: la prensa y la literatura, actividades que alternó y fusionó con la militancia política. 
Con una cierta dosis de ambición, es posible afirmar que la historia de la izquierda mexicana es en gran medida la biografía de Revueltas: los caminos que se trenzaron en su andar son también los de una opción socio-política nacida cuando el olor a pólvora de la guerra civil aun se encontraba en el ambiente político y que a la postre sería el inicio de un conjunto de transformaciones que modificarían a la sociedad en su conjunto, sobre la base de un "shock" modernizante de grandes proporciones. Esto no sólo en un aspecto formal, pues la modernización heredera de la guerra civil forjó su propia jaula de hierro a partir de la cual se establecieron los marcos para pensar y socializar, así como de realizar la práctica política. La izquierda habitó en aquella cárcel impuesta por la ideología pos-revolucionaria, perseguida, minoritaria, periférica, dependiente, pero presente de manera constante, tanto con intervenciones puntuales como reflexionando sobre lo que sucedía en el país.

El proceso de superación de las constantes crisis de identidad de quienes afirmaban la necesidad de un tipo de revolución en un país que venía saliendo de una, muy costosa en términos humanos, no fue sencillo. La tutela ideológica ejercida por el Estado fundado tras la guerra civil perduró hasta la segunda mitad del siglo XX. Es en el conjunto de este proceso en donde Revueltas hace parte del cúmulo de pensadores que ejercita la crítica, tanto del Estado como de la izquierda misma. En 1961, ya en su madurez política e intelectual, redacta el que será uno de sus textos no literarios más afamados, verdadera referencia en el tránsito de las izquierdas mexicanas: el Ensayo sobre un proletariado sin cabeza. Publicado de manera independiente, recibe algunas reseñas elogiosas (González Rojo 1962; Aguilar 1962) y algún comentario crítico de dicha reseña en la pluma de Enrique González Pedrero, pudiéndose considerar que en su momento fue un texto más bien marginal, en gran medida porque su destino no era otro que el conjunto de militantes a quienes interpelaba a partir de determina nomenclatura. Es, sin embargo, al calor de los vientos de democratización que hacia los años ochenta impulsa la izquierda es que el Ensayo se transformará en un referente obligado y el punto de arranque desde el cual se expresan renovadas valoraciones al pasado de las expresiones partidarias.

En el marco de esta historia o de esta multiplicidad de historias que se tejen alrededor de la figura de Revueltas plantearemos en este texto una aproximación crítica. La cultura política de izquierda se ha visto nutrida a partir de la aparición del famoso y multicitado Ensayo sobre un proletariado sin cabeza, pues en el se condensaban las principales críticas a la fuerza principal de esa opción política. El tránsito que sufrió la obra, entre una consideración marginal (escrito desde una secta marxista), a una referencia 
obligada, no fue menor y expresa operaciones de lectura ejercidas en determinas coyunturas, destacando su paso como un texto que expresaba las pugnas al interior de los grupúsculos de izquierda, a ser considerado una especie de balance histórico de la izquierda. Este tránsito fue el que permitió un determinado énfasis en la aproximación.

Este texto apuntala los inicios de una lectura crítica de una de las figuras más importantes del marxismo en la región, en un texto capital. La exposición constará de cuatro partes. En la primera de ellas se establecerá la manera en que procedemos a operar el ejercicio de trabajo teórico siguiendo el legado intelectual heredado por Louis Althusser, que funcionará para establecer las líneas de demarcación necesarias para entender la ambivalencia del contenido. En el segundo apartado se realizará una revisión de ciertas aproximaciones que el Ensayo ha suscitado y resultan pertinentes para nuestro argumento y la aproximación crítica. En la tercera sección se expondrá el núcleo central de la lectura crítica a partir de la consideración de que en el texto de Revueltas conviven dos lógicas discursivas fundamentales, que de hecho expresan las dos maneras en que el escritor duranguense practicó el marxismo. Finalmente, se aventurará una hipótesis que rebasa el contenido del Ensayo, pero busca darle una salida a las hipótesis.

\section{Lecturas de un texto teórico}

¿Cómo leer un texto afincado en la tradición marxista? ¿Es posible problematizar el conjunto de elementos que se presupone como una unidad indisoluble? ¿O sólo es posible ubicarlo en un plano meramente "contextual", en dónde son sus referentes inmediatos los que le otorgan un sentido? Este ha sido uno de los dilemas principales para la tradición marxista que ha reflexionado sobre su propio pasado.

A lo largo del trayecto se han desarrollado perspectivas que buscan dar respuesta a esta temática. Tenemos al menos dos posiciones claras que con sus variaciones, fueron dominantes durante la primera mitad del siglo XX. La primera es la que denomino lectura historicista, que podría señalarse como aquella que coloca empeño en discernir las condiciones históricas inigualables en las que se enmarca una producción. Así, en la línea historicista, El Capital no podría ser otra cosa que la radiografía más precisa del capitalismo inglés de la época victoriana, una especie de pre-historia permanente de cualquier otra modalidad histórica (la imperialista, la del estado de bienestar o la neoliberal, según se elija). Por otro lado, tenemos la perspectiva que podemos denominar una lectura metodologicista, formulada a partir de la intervención de Gyorgy Lukács en su conocida obra Historia y Conciencia de clase, que expresaría el 
anverso de la primera, pues insistiría en la condición de universalismo: se trataría de discernir el método que se moviliza en el interior de un texto teórico para remarcar los elementos que operan de forma apriori, es decir, se destacaría la herramienta de conocimiento (la abstracción es el ejemplo más socorrido) que serviría para cualquier objeto, en cualquier tiempo y en cualquier espacio. En el primer caso, no podemos rebasar determinadas fronteras impuestas por una "época histórica" o una cierta geo-cultura; en tanto qué, en la segunda, nos enfrentamos al imperio de la abstracción de un método que aspira a la universalidad y a la totalidad plena.

Este problema acompañó a gran parte de la tradición marxista que pretendió desarrollar el campo teórico como un espacio autónomo y específico de reflexión. El año de partición de esta dualidad fue 1965 con la aparición de los trabajos de Louis Althusser y con ellos, una nueva forma de concebir el espacio de la teoría. A lo largo de su trayectoria, el filósofo francés propuso diversas estrategias para salir del atolladero (lo que después sería conocido como la "crisis del marxismo") qué, según él, habían orillado las dos perspectivas anteriores en su difusión y dominio prácticamente absoluto. No fue, sin embargo, hasta el final de su vida, en que esa forma de tratamiento quedó asentada de manera mucho más clara en todas sus consecuencias.

Tomamos como hipótesis de lectura la realizada por el francés respecto a El Capital. En uno de sus trabajos póstumos (Althusser 2003: 55), el filósofo francés señala que es preciso cuestionar la unidad aparente del texto para poder trabajar teóricamente con él. Lo que apuntalaba era un tratamiento del texto en tanto que un conjunto de discursos o lógicas que no necesariamente se seguían las unas a las otras, que mantenían independencia y eran productivas por sí mismas. Esto se traducía en su recomendación de no comenzar la lectura de El Capital de Marx a partir de sección primera, sino de la segunda (Althusser 2004: 33), es decir, no someterse al inicio que demostraba la aparente necesidad de la equivalencia de mercancías, sino justamente a la inexistencia de dicha equivalencia, situación que permite la explotación del trabajo humano. De igual forma en su texto póstumo titulado Para un materialismo aleatorio, sugiere que el capítulo XXIV es el que expresa la escritura materialista dentro de El Capital, pues en su interior opera un escape de toda filosofía de la historia (contrario a la sección primera, que nos colocaría en el despliegue automático de la historia del valor que se valoriza) y se colocan las condiciones materiales para la reproducción de las relaciones de producción: la expropiación del productor directo (Althusser 2002: 68). 
Así, Althusser afinó plenamente en su texto Ser marxista en filosofía (2017) lo que consideraba era una condición de todo texto teórico marxista, comenzando por el propio Marx: la convivencia permanente e irresoluble de, al menos, dos tendencias. Para el francés, bajo el nombre de idealismo y materialismo no se nombraba a dos filosofías contrapuestas e independientes, sino que se trataba de dos posiciones que se jugaban al seno de toda la tradición occidental. Si bien el día de hoy la nomenclatura aparece anticuada, lo cierto es que bajo esos nombres se labraba la existencia de una dualidad al seno del marxismo. ¿Pero qué era lo que quería expresar Althusser con los nombres de materialismo e idealismo? No, obviamente, la caricatura repetida a la saciedad en el marxismo "ortodoxo": la materia u objetividad que vencen a una abstractas “ideas".

Para Althusser idealismo y materialismo son dos tendencias filosóficas que Marx habría expresado de manera prístina en su producción a partir de varios emplazamientos, a saber, una consideración sobre la historia, sobre la garantía de su desarrollo y sobre su devenir o realización. De un lado, la tendencia idealista, afincada en el gran devenir universal a partir de una filosofía de la historia, cuya garantía era la existencia de un sujeto trascendental que realizaría la historia y la filosofía misma. Para decirlo con un lenguaje más tradicional, la perspectiva idealista es aquella en donde el desarrollo de las fuerzas productivas (la ciencia, la técnica) apuntalaría a un sujeto universal (el proletariado) que, al encontrarse en mejores condiciones de lograr el control de la naturaleza, dado su lugar privilegiado en la producción, podría finalmente dominarla por completo, abriendo la posibilidad de abolir todo signo de explotación y de establecer en la sociedad una relación plenamente transparente.

Frente a la posición idealistas (Althusser 2017: 48), que aparecería repetidamente tanto en Marx, como en Lenin o prácticamente en cualquier otro espacio de reflexión asociado al comunismo en tanto movimiento histórico, Althusser opondría lo que denominó cómo una tendencia subterránea o reprimida: la materialista. Se entiende que se trata de la versión contraria, en donde las tres señas de identidad antes mencionadas se verían modificadas. Así, no se colocaría el acento en una filosofía de la historia, sino en una temporalidad contingente, abierta a partir de las distintas coyunturas (espacios/tiempos de toma de postura), horadando cualquier lugar privilegiado para un sujeto trascendental y por tanto cancelando cualquier garantía última (el proletariado no es más ya la clase universal); todo ello dando como resultado la "crisis del marxismo", entendida esta como la discusión desarrollada tras el reconocimiento de que una sociedad en plenitud era una tarea imposible. Con la posición materialista Althusser invitaba al abandono 
de toda certeza y al cuestionamiento de los avances de sociedades que se declaraban en camino hacia la superación de sus contradicciones.

Althusser trabajó en un primer momento con la nomenclatura que afirmaba la existencia de "dos Marx", uno de juventud y otro de madurez, entre los que mediaba una "ruptura epistemológica". Aquello que era una metáfora para indicar la aparición de un espacio de producción teórico no dependiente de otras corrientes (el "idealismo alemán o la economía política inglesa”) se confundió con la descripción del desarrollo cerebral de un individuo. Los críticos no entendieron que cuando el francés hablaba de la madurez o juventud de Marx se refería a la formulación de ese espacio teórico y se lanzaron con fiereza sobre la división, especulando sobre la vida de un individuo muerto hacía mucho tiempo. Hacia el final de su producción - mucha de ella publicada póstumamente- Althusser reconoce que en Marx no existió una "ruptura epistemológica" total y que en lo que antes se denominaba el "Marx maduro" seguía actuando la presencia del idealismo (Althusser 2015:155), dando pie al abandono de la nomenclatura asociada al desarrollo individual. De igual manera, abría la posibilidad de una lectura materialista de las obras de juventud, tarea inconclusa hasta tiempos recientes. La aportación metodológica para pensar el texto marxista resulta crucial, pues coloca la unidad como una apariencia y permite reordenarlo de acuerdo a las exigencias de la coyuntura. El francés no renunciaba a la categoría de totalidad, pero no la daba esta por supuesta, habría que realizar un trabajo teórico para la reconstrucción de ella.

Después de Althusser han sido pocos los que han acometido una lectura filosófica del texto marxista de El Capital, pues dentro del campo de la filosofía se han acotado al comentario puntual de las secciones o los capítulos. Sin embargo, en su momento el ex althusseriano Gabriel Albiac (1977) dio anotaciones sugerentes para pensar esta "unidad ficticia” y captar el despliegue de lógicas que atravesaban El Capital, siendo sus aportes de los más sugerentes en español. Un ejemplo más reciente lo encontramos en El orden de El Capital (2010) y Marx desde cero (2018) de Carlos Fernández Liria y Luis Alegre Zahonero, quienes llevan a sus últimas consecuencias el planteamiento de Althusser. Estos dos filósofos españoles reflexionan sobre la imposibilidad lógica de pasar de la sección primera ("mercancía y dinero") con su correspondiente exposición a propósito del intercambio mercantil equivalente, con respecto a otras zonas de El Capital, tal como el concepto de plusvalor o la exposición del capítulo XXIV, que hablarían no de pequeños propietarios privados que intercambian en condiciones de igualdad, sino de la violencia fundante de las relaciones sociales que dividen a la sociedad moderna en clases. 
De una manera similar a la propuesta de Althusser es que pretendemos operar con respecto al texto de Revueltas. Sostenemos entonces que el texto del escritor mexicano contiene al menos dos discursividades contrapuestas, pero que conviven en el texto. Este hecho ha sido señalado a una nota a pie por Juan Manuel Mateo y nos parece que es el punto de inicio para realizar una lectura crítica del documento más famoso de crítica de la izquierda mexicana, desde el punto de vista del marxismo.

\section{La multiplicidad deviene uno: recepciones del Ensayo}

Sostener que existen sólo dos tesis es casi tan unilateral como apostar a una unidad indiferente, es preciso señalar la forma de operación de ambas. Sin embargo, han sido pocos los autores que han revivido esta cuestión al interior de la obra del autor que ahora convocamos. Evodio Escalante (2015), uno de los más interesantes e importantes estudiosos de Revueltas, ha señalado cómo la tesis de la "inexistencia histórica" de la vanguardia había sido labrada al menos diez años, en el seno de su producción literaria. Una cantidad significativa de autores han reiterado esta tesis.

La veta que explora la dimensión literaria es amplia; sin embargo, ahora privilegiaremos aquí tres autores, que, desde nuestro punto de vista, han logrado contribuir significativamente a la problematización del registro teórico-político. El primero de ellos es Jorge Fuentes Morúa (2001) quién en su aporte, nos otorga las herramientas necesarias para comprender el porqué Revueltas se encuentra tan comprometido con el lenguaje hegeliano-marxista. A lo largo de su trabajo, el biógrafo demuestra que la obra de Revueltas tanto literaria como teórica- debe enmarcarse en una temprana y profunda lectura de los Manuscritos de 1844. El énfasis de Revueltas en los temas de la enajenación, la conciencia y el desgarro que se produce en la vida social, se debe, directamente, al tipo de lectura hegeliano-marxista que emprende. En el caso del libro de Fuentes Morúa se rastrea la edición temprana de los manuscritos del “joven Marx”, fechados hacia el final de los años treinta en la traducción de Alice Gerstel. Aún más, este autor demuestra como la obra del escritor duranguense posee una clave de lectura a partir de la problemática contenida en los famosos manuscritos, mucho más evidente en sus figuras literarias, pero también presente, como lo demuestra el lenguaje del Ensayo, en el ámbito de lo teórico-político. ¿Qué es el proletariado sin cabeza sino un sujeto que no es autoconsciente de su lugar en la historia? ¿No es el proletariado sin cabeza el cuerpo que piensa y se piensa con una cabeza que no es la suya? ¿No es este el punto más radical de la enajenación en la descripción hecha por el joven Marx cuando refiere a la enajenación con respecto al 
trabajo en tanto actividad creadora fundamental? Fuentes Morúa entrega los principales argumentos historiográficos para comprender el énfasis revueltiano con respecto al tema de la enajenación y emprende un ejercicio de desarrollo de esa hipótesis.

El segundo autor que ha encontrado una veta problemática es Arturo Anguiano. En su reciente libro sobre el "rebelde melancólico" ha trazado las principales contradicciones que aparecen en el tema partidario, así como un balance bastante mesurado con respecto al texto. Dice Anguiano: "El Ensayo sobre un proletariado sin cabeza, contiene empero resabios de esquemas acartonados, mitos doctrinarios y posiciones que más tarde cuestiona y siente necesidad de revisar, a veces ya sin lograrlo. En verdad conviene leer el conjunto de sus ensayos en una cronología invertida, y no sólo temática" (Anguiano 2017: 89). Esto es así porque en una marca de época: “[...] pasarán varios años que para Revueltas son de búsqueda obsesiva por la construcción del partido de la clase obrera, de un auténtico partido comunista, marxista leninista [...]" (Anguiano 2017: 194). Así, "Su visión y su confianza en la URSS y el campo socialista, explican que Revueltas todo el tiempo vea al Partido Comunista Mexicano como un problema singular, específico, mexicano, diferente a los demás partidos comunistas [...] El ensayo sobre un proeltariado sin cabeza es pues rebasado por Los Errores" (Anguiano, 2017: 215-217).

Finalmente, Juan Manuel Mateo, quien en los últimos años se ha instalado como uno de los referentes principales para pensar un conjunto de temáticas a propósito de Revueltas, ha hecho un ejercicio sugerente de interpretación del Ensayo con respecto a Ricardo Flores Magón. En Tiempo de Revueltas dos: la discordia proletaria, ha recuperado la hipótesis sobre el cómo el "éxito" de la tesis a propósito de la inexistencia histórica, ocultó otras posibilidades de lectura. En su ensayo, polemiza con Rodríguez Araujo y Domínguez Michel (dos autores en las antípodas de la posición política) para señalar que "junto a la teoria del partido pueden distinguiste otras dos líneas fundamentales” (Mateo 2016: 109).

La recepción del Ensayo fue numerosa, hacer referencia a estos tres autores nos remite a las principales coordenadas que nos interesa discutir aquí. Con fuentes Morúa asediamos las condiciones materiales de la producción intelectual, que en este caso refieren a la podersa influencia de la problemática del joven Marx, el de los Manuscritos de 1844. Con Anguiano a las contradicciones políticas en la redacción, que navegan entre el ascenso del movimiento ferrocarrilero y las coordenadas históricas del "leninismo". Con Mateo, a la crítica del supuesto de una sóla hipótesis de lectura y por tanto a la posibilidad de fomentar 
otras vías. Señalamos, finalmente, que González Rojo regresó a discutir de manera profunda este tema en su connotado Ensayo sobre las ideas políticas de José Revueltas (1987), texto ineludible, al que volveremos más adelante

\section{Las dos tesis del Ensayo}

Podríamos señalar que el Ensayo está atravesado por dos lógicas discursivas (o una dualidad de tesis), que se superponen la una con la otra y conviven problemáticamente, aunque amalgamadas a partir de la intención de Revueltas: aquella en la que la filosofía de la historia en toda su profundidad hace parte también de las discusiones de coyuntura. Metafóricamente podríamos decir que el duranguense observa con un telescopio aquello que demanda un microscopio. Por un lado, denominaremos tesis "idealista" a aquella que enganchada en el lenguaje hegeliano apuntala la categoría de "inexistencia histórica" del PCM. Del otro, la "tesis materialista", de la cual debemos entender la explicación de la forma histórica del dominio en México tras la emergencia del Estado creado en la pos-revolución. Son dos momentos que habitan al texto, lo organizan y permiten definir el lenguaje tanto categorial como el posicionamiento político, marcando así los límites de su perspectiva.

¿Qué es lo que nos permite que existe una posición o tesis idealista, de acuerdo a la definición antes dada? Lo primero que habría que señalar es una motivación de filosofía de la historia, en donde el "progreso" aguarda un lugar privilegiado y es el mirador a partir del cual se evalúa el conjunto del despliegue de la historia. Así, podemos leer qué para referirse a México, escribe lo que sería una ambigüedad donde la “conquista española" sería el establecimiento de las relaciones "retrógradas" con respecto al capitalismo mundial, pero progresista frente a las sociedades existentes previamente. Dice:

No obstante que la conquista -y según me parece, será la primera vez en México que se externe una opinión de tal índole desde el punto de vista de la izquierda marxista-debe considerarse, en mi opinión, como un elemento progresivo del desarrollo en lo que respecto al estado social e histórico del Anáhuac -con perdón sea dicho de los indigenistas-, si se toma, en cambio, dentro del conjunto de las relaciones de producción que se gestaban en su tiempo, es un fenómeno retardatario, reaccionario. Constituye un fenómeno progresista en tanto suplanta un sistema que apenas se encuentra en la etapa superior de la barbarie por un sistema más adelantado, pero es un fenómeno de retroceso en tanto no hace sino trasladar al Anáhuac -y a toda la América conquistada por España, agravándolo, el feudalismo de la península. (Revueltas 1984: 146). 
Este párrafo muestra los límites de la concepción que aun impera en su pensamiento. Un horizonte teleológico, de progreso y desarrollo, combinado con una concepción en donde etapas predeterminadas tienen que ocurrir. Apenas una veta crítica podría asomarse en la consideración del capitalismo mundial como sistema, pero atrapado en una noción donde hay atrasado y desarrollo definidos de ante mano, operando como medidas de la historia de los pueblos y naciones.

Esta concepción tiene impacto en el orden estrictamente político y no sólo de valoración de la historia del país. Es por ello qué en el Ensayo aparece una confianza desmedida en la existencia de la URSS. Recordemos que Revueltas habla en la época del gobierno de Nikita Kruschev, la de la "des estalinización” y que carga con los primeros saldos de la represión soviética a las revueltas en Berlín y Budapest. En el escritor sin embargo, la época puede ser considerada como de progreso, pues "la existencia de un sistema de países socialistas acelera el ritmo del proceso revolucionario en todo el mundo, porque, en lo fundamental, representa la superación de las limitaciones de la época precedente, en que sólo existía un país socialista” (Revueltas 1984: 65) Ello le lleva a justificar la geopolítica del momento: “....la coexistencia pacífica entre países con diferentes regímenes sociales adquiere una connotación revolucionaria de primer orden" (Revueltas 1986: 66) y también a dar un fallo, en la clave que sostenemos, que enmarca la tesis idealista: "La derrota del capitalismo se ha consumado en la historia, aunque todavía no se consume de una manera total en la práctica inmediata." (Revueltas 1986: 67).

Como hemos señalado en la definición a propósito de la tesis idealista, siguiendo a Althusser, esta se caracteriza en gran medida por su consideración de la historia que avanza en un sentido, es decir, posee un telos. Revueltas, como parte de la tradición marxista de principios de siglo XX, continúa esta senda: la historia tiene un sentido en la medida en que las fuerzas productivas sean desarrolladas y el proletariado pueda encausar su uso destructivo (la bomba atómica) por uno productivo (el socialismo). El progreso social sólo puede ser leído en esta clave y la existencia de la Unión Soviética constatarían esta situación, al grado de proponer la "coexistencia pacífica” como una vía del desarrollo de la historia y no como el recurso geo-político de una potencia con respecto a otra. Es preciso preguntarse, sin embargo, si esta es la única característica que envuelve la problemática de Revueltas. 
Es evidente que además de esta, existen otras nociones que completan la tesis idealista. Junto a la concepción teleológica de la historia, se coloca la consideración de un sujeto pre-existente, cuya misión en la historia es justamente dotarle un sentido progresista a su desarrollo. En el argumento de Revueltas, como en mucho del marxismo de la época, la burguesía ha dejado de ser revolucionaria y progresista y ese papel ahora le corresponde a esa clase a la que se le asignó una "misión histórica": el proletariado industrial. Como ha señalado Anguiano, en Revueltas opera una noción distante del campesino y la denominada centralidad proletaria se asume como un hecho incuestionable.

Es evidente que Revueltas juega aquí, nuevamente, en un nivel trascendental. No observa la especificidad del tiempo y espacio, sino el papel de un sujeto que debería totalizar la vida social y proyectarle un sentido a la historia en su conjunto. El fallo que ve Revueltas, uno de los motivos principales del Ensayo, es justamente que la versión nacional-empírica del proletariado no cuenta con el instrumento para ejercer su papel de la historia y de hecho en esta, apenas y tiene un papel secundario. Aquí el lenguaje asume por completo las categorías de necesidad, auto conciencia y realización. El proletariado mexicano debería tener una conciencia socialista (que no sería otra cosa que su auto conciencia), pero carece de ella. Igualmente, el proletariado debería poseer un partido que fuera su vanguardia, pero este se encuentra ausente. El proletariado debería realizar la historia en un sentido progresivo, pero al no poseer partido de vanguardia ni tener autoconciencia, no puede lograrlo. Revueltas indica que esta es una anomalía exclusivamente mexicana: "En México se produce un fenómeno del que difícilmente puede darse un paralelo en ningún otro país del mundo contemporáneo. Este fenómeno consiste en que la conciencia de la clase obrera ha permanecido enajenada a ideologías extrañas a su clase y en particular a la ideología democrático-burguesa, desde hace más de cincuenta años, sin que hasta la fecha haya podido conquistar su independencia" (Revueltas 1986: 75). Y remata, justamente, con la síntesis que da sentido a todo su argumento: "La clase obrera mexicana, de este modo, se proyecta en la historia de los últimos cincuenta años del país como un proletariado sin cabeza, o que tiene sobre sus hombros una cabeza que no es la suya" (Revueltas 1986: 75)

Aproximarse críticamente al texto puede ser un camino que se inicie a partir de la formulación de preguntas sencillas y básicas, que no por ello, inocentes. Valdría la pena, entonces, cuestionarse: ¿Cómo es que hay tanta certeza de que el proletariado debe tener una sola ideología de manera necesaria? ¿Cómo es que existe un conglomerado heterogéneo que puede ser reducido a un concepto totalizante 
independientemente de su composición sexual, étnica o nacional? ¿Quién decide sobre la conciencia correcta e incorrecta que determinados sectores sociales despliegan? Para Revueltas estas preguntas son innecesarias, pues la perspectiva se ancla en un conjunto de certezas que resultan inamovibles, comprobadas en otras experiencias (la Unión Soviética) y sólo en el caso mexicano aparecen como falencias: el proletariado debería tener una ideología comunista, que serían la expresión verdadera de sus intereses y partiendo desde ella construir un único partido mediante la cual realizaría dichos intereses. Al proceder siguiendo este guion, la clase explotada mexicana en realidad cumpliría una misión en la historia, al darle un sentido de avance y progreso, que se cierne tras la barbarie nuclear que representa la burguesía.

La tesis idealista que opera en el ensayo es clara en el sentido de la filosofía de la historia y la consideración de un sujeto trascendental -colocado más allá de las prácticas concretas-que debería actuar en su interior. El lenguaje que moviliza es plenamente hegeliano y esto lo ha demostrado con creces Fuentes Morúa en su exploración sobre la “antropología filosófica” revuelitana. En esta tesis un sujeto que no tiene existencia empírica, sino solo conceptual, tendría que expresar su auto conciencia como productor del mundo, pero al encontrarse enajenado, piensa y actúa con una cabeza (conceptos, teorías, sentido común) que no es la suya. Al hacerlo así, en realidad mira, piensa y actúa como otro sujeto. La tarea de los comunistas debería ser corregir esta situación, pero al no ser parte de la solución hacen más bien parte del problema, son "la enajenación comunista de la clase obrera” (Revueltas 1986: 80)

Hasta aquí el esfuerzo de dilucidar la posición o tesis idealista que circula a lo largo del ensayo, tal como se definió en la segunda sección. Sin embargo, no es esta la única perspectiva que habita sus páginas. El compromiso con el lenguaje hegeliano es tan potente, que por momentos para absolutizar el conjunto del texto y parece delinear una sola perspectiva. Sostenemos, en cambio, que existe una tesis o posición materialista que interactúa con esta y como mencionamos antes, convive con ella. En esta perspectiva abandonamos el terreno de la filosofía de la historia y podemos pensar más bien en términos de la evaluación de las coyunturas. No es la primera ocasión en que Revueltas evalúa una situación, en donde la relación de fuerza y las posibilidades y debilidades de los contendientes de la arena política son puestas en perspectiva. Esto lo hace, por ejemplo, en México una democracia bárbara de manera magistral, al analizar la sucesión presidencial que abrirá el camino al ascenso de Adolfo López Mateos. Sin embargo, en el Ensayo se encuentra esta perspectiva débilmente trazada, en su escasa presencia -un diagnóstico 
sobre el devenir de la forma política concreta de México-alterna con el lenguaje hegeliano y sus vertientes de filosofía de la historia y de la conciencia. Por ejemplo, señala Revueltas:

Entiéndase bien: no es que "los gobiernos emanados de la revolución" se muestren intolerantes y adversos ante todas y cada una de las luchas obreras; no los gobiernos de la burguesía nacional han combatido, combaten y combatirán siempre aquellas luchas proletarias donde la clase obrera, como tal clase, aparezca con su fisonomía independiente y quiera imponer al Estado sus demandas por medio de la fuerza, pero tolerarán otras luchas donde no existan estas circunstancias y los trabajadores se constriñan a pelar de modo exclusivo por sus intereses económico limitado. (Revueltas 1986: 167).

Revueltas logra captar el elemento fundamental de la dominación política en el México de la primera mitad del siglo XX: el control sobre las clases sociales que desde el Estado se ejerció con firmeza. En su comprensión cabal de este fenómeno, escribe:

El partido de la burguesía nacional, así, funciona como una especie de "extensión social" del Estado, que de ese modo hace penetrar sus filamentos organizativos hasta las capas más hondas de la población e impide con ello una concurrencia política de clase. Repetimos: no cualquier concurrencia política, puesto que el partido oficial aun se permite hasta una concurrencia "obrera" sino de un modo preciso y tajante, toda concurrencia independiente [...]. (Revueltas, 1986: 168-169).

La fortaleza del Ensayo, desde el punto de vista de la noción de materialismo -heredada, como dijimos, de Althusser- es que traza los elementos necesarios para construir el entendimiento de la estabilidad del régimen político. Este se afincó, con claridad a partir de los años treinta, en el control corporativo de la sociedad y fue avanzando en la medida en que el proletariado mismo creció. Los mecanismos de control, que llegaron a su climax con el "charrazo" de 1948 actuaron de manera determinante en el periodo 56-59, cuando se culmina un ciclo de luchas, al momento de la mayor represión al movimiento ferrocarrilero (Ortega 1988). El partido "oficial” como extensión del Estado en la sociedad, los sindicatos como organizadores y movilizadores en la reiteración del festejo al presidente, las organizaciones campesinas como contenedoras del fracaso de la reforma agraria, son solo algunos de los momentos de esta estela de dominación, que al final encuentra en un solo punto su entendimiento: la falta de autonomía de las clases subalternas. 
Este es el aspecto fundamental, el de la forma corporativa del dominio sobre la sociedad, que suele ser acompañado en las discusiones marxistas sobre el carácter del Estado. Revueltas se coloca del lado de quienes considera que es la burguesía la que controla y dirige el proceso social después de la revolución. La temática fue poco discutida en la época del dominio de la "ideología de la revolución mexicana” y sólo eclosionará en los años sesenta y setenta, cuando la izquierda rompa definitivamente con ella. Este punto es crucial, pues en el mismo momento tanto el PCM como su gran crítico -Revueltas-dan el inicio a esta ruptura con la forma de comprensión del desarrollo capitalista y el lugar del Estado en él.

Otros contingentes de la izquierda no lo lograrán romper por completo con el espectro ideológico dominante, que afirmaba que una posible revolución socialista sólo es posible por el camino abierto por la revolución mexicana. En horizonte de tipo teleológico, el socialismo debía ser la consecuencia del desarrollo del proceso abierto en 1910. Por ejemplo, es de señalarse los casos de Lombardo Toledano, quien jamás rompió con aquella perspectiva y de hecho se comprometió más con ella. O bien, Miguel Aroche Parra, quien escribió paralelamente a Revueltas un ensayo de interpretación que insiste en la necesidad de la alianza con sectores de la burguesía. No es el caso del PCM, donde esta ruptura viene labrándose desde 1959 y se profundiza en los años sesenta.

Vale la pena profundizar un poco más en las consecuencias del planteamiento del escritor duranguense. Ello remite necesariamente a la conflictiva relación con el PCM, organización con la que no volvió a tener puntos de contacto, justo cuando más coincidía con algunas evaluaciones. Para el PCM a partir del año 59 y en adelante, el tema principal será el de la posibilidad de ejercicio de autonomía por las clases subalternas, temática que tomará la forma de intentos de eludir el control corporativo, no ciertamente entre el proletariado, por entonces diezmado por la represión, sino sobre todo en el mundo campesino (De la Fuente, 2015). A partir de esa década las evaluaciones del PCM sobre la revolución mexicana son abiertamente críticas, considerado que la autocrítica pasaba por la manera en que se ofrendó la autonomía del propio partido en algunos procesos en las décadas anteriores.

Los senderos que recorrerán las elaboraciones en lo individual de Revueltas y en lo colectivo del PCM se tocarán en sus grandes conclusiones: no había ya espacio para la "revolución mexicana" en el horizonte socialista y este debía transitar por otra ruta. Así, entre los comunistas comenzaba a realizarse cada vez más la crítica a la ideología oficial en las plumas de Enrique Semo y Gerardo Unzueta, por ejemplo. 
Incluso, adelantándonos en la línea cronológica, es posible pensar los puntos de empalme entre el partido y Revueltas en el año 68, en donde se sostiene una posición similar frente a la represión: la necesidad de levantar la huelga y abrir el movimiento hacia la sociedad.

No queremos hacer un atropello de las diferencias. Entre Revueltas y el PCM siguieron existiendo distancias abismales, tanto en el uso de la teoría, como en las cuestiones tácticas y estratégicas de las caracterizaciones. Sin embargo, vista a la distancia, existen algunos puntos de contacto, producto de un desarrollo convergente de posiciones producto de la autocrítica. Escribe Enrique Semo, connotado historiador y militante del comunismo: "Formábamos parte de dos procesos muy diferentes de la izquierda en aquellos años: Revueltas, la culminación de la crítica de toda una época histórica; un ajuste de cuentas con un pasado que él había vivido. Nosotros, un grupo que ingresaba al movimiento sin conocimiento de ese pasado, impulsados por las luchas obreras y la represión llenos de esperanzas y de ingenuidad. Nuestro punto de partida no podía ser la negación revueltiana" (Semo 1988: 103). En una época de sectarismos, agrandar las diferencias era algo común y estas se expresaban en todas las aristas, tanto personales como políticas, confundidas y atravesadas las unas y las otras. En el paroxismo de esta práctica sectaria al propio Revueltas le costó ser expulsado de una organización que fundó, cuando mantuvo posiciones igual de intolerantes que las que solía criticar (González Gómez 2017: 102), según se sabe por testimonios contemporáneos.

En el Ensayo, Revueltas traza una primera línea de crítica a la revolución mexicana. Ella encuentra su fortaleza en la disposición de los elementos históricos y contextuales de la forma de dominación. En cambio, su debilidad reside en la utilización de una perspectiva afincada en la necesidad histórica y, por tanto, en cierta astucia de la razón. Su escepticismo sobre el PCM -justo, tras dos décadas de crisis de esa organización- no debe oscurecer lo que el Ensayo si permite esclarecer. A continuación, redondearemos la crítica a este crucial texto.

\section{¿Proletariado sin cabeza o un cuerpo social domesticado?}

El final del recorrido de nuestro texto nos plantea los elementos más importantes para la discusión de un autor central en la tradición política de la izquierda. Realizar un ejercicio de lectura y crítica de José Revueltas, es, al mismo tiempo, un ejercicio de lectura del propio siglo XX y de la forma en que los mecanismos de dominación política e ideológica se desplegaron con efectividad. Más allá de las 
condiciones internacionales -marcadas por la guerra fría- el escritor duranguense es una presencia constante en la reflexión sobre la especificidad del Estado y sistema político mexicano. Junto a Octavio Paz o Daniel Cosío Villegas, pero en vereda opuesta ellos, Revueltas busca captar la lógica del funcionamiento de un Estado que resulta tan incapaz por momentos, como tan eficaz y efectivo en otros.

Ello nos lleva a concentrar nuestra crítica en el espacio abierto por la tesis idealista que mora gran parte del texto. Hemos señalado que Revueltas emplaza con un lenguaje específico una elaboración sobre el estatuto de la izquierda y ello, en el mejor sentido, es decir, busca responder a un problema real de la coyuntura, que tiene múltiples expresiones. Para ello utiliza las categorías y concepciones del "idealismo alemán" como llave privilegiada para desentrañar la época histórica. Ello lo llevó por a trazar sendas en donde nociones como "alienación” o "inexistencia histórica” tomaron forma como medidores de una realidad empírica enmarcada en el desarrollo de un Estado que logró contener la movilización social, así como contener y controlar a las distintas oposiciones (no sólo a la izquierda). Para Revueltas, la capacidad del dominio político estaba en gran medida posibilitada por la ausencia del "cerebro" o la "vanguardia" que lograra el proceso de la auto conciencia del proletariado.

Es justamente en este elemento donde es necesario realizar la crítica, pues, aunque emplaza un problema real, al privilegiar la tesis idealista, confunde la consecuencia con el resultado. Hacia el final del Ensayo escribe:

La raíz esencial de la falta de independencia de la clase obrera en México hay que buscarla precisamente en el punto donde radica la enajenación esencial de ésta: en el papel que ha representado el Partido Comunista Mexicano como conciencia obrera deformada, como partido que no ha podido ser el auténtico partido de clase del proletariado, después de más de cuarenta años de existencia física. (Revueltas 1986: 222).

Más allá de lo problemático que resulta para una evaluación materialista aceptar que algo que existe físicamente no existe históricamente, el punto central se encuentra en otro lado. Hay que abandonar la discusión sobre el nivel de las categorías hegeliano-marxistas, que fue el que atrajo a críticos y detractores desde la publicación del Ensayo, como lo fue el primer debate que se suscitó entre Enrique González Rojo y Enrique González Pedrero en la revista Política. Por el contrario, hay que concentrarse en la relación entre la independencia de la clase y el estatuto de la izquierda, ambas en relación con el Estado. La problemática planteada resultaba candente, pues tanto la izquierda y no sólo el proletariado había 
mantenido una posición dependiente de la "ideología de la revolución mexicana", que se configuraba a partir de la idea de que al socialismo se llegaba por la vía de la radicalización de esta; en tanto que tomaba forma en la subordinación al partido oficial. Pero al contrario de lo que piensa Revueltas, es posible afirmar que esta situación se debe a la forma de dominación estatal y no a una ausencia de lecturas de Marx o de Lenin o a una mala caracterización partidaria sobre la burguesía. Es decir, el planteamiento problemático es correcto, pero la resolución equivocada: la ausencia de independencia ideológica de la izquierda y de la clase se explica a partir de las formas de dominio establecidas desde los años treinta y no al revés.

Revueltas organizó su planteamiento a partir de una noción teleológica, enmarcada en una filosofía de la historia que devino proyecto político. En ella, el capitalismo era un régimen mundial en el que las fuerzas productivas habían agotado sus perspectivas "progresistas". La obsesión por la guerra nuclear que aparece en textos políticos y literarios no es sino expresión de esta evaluación. El dominio de la naturaleza a partir del despliegue de la ciencia y la técnica sólo era posible en un régimen social distinto: el socialismo. Sin embargo, esta perspectiva sólo podía ser realizada a partir de la victoria de una clase social: el proletariado. Según Revueltas, el capitalismo había sido ya derrotado en términos históricos (es decir, de su devenir) pero faltaba la confirmación de esto, siendo México un caso excepcional, una rareza, en donde el proletariado no era revolucionario.

Para Revueltas, como para los marxistas de su época, el proletariado era la clase antagónica del capital. Esta perspectiva fue dominante entre los teóricos e intelectuales comunistas y de otras vertientes. Fue hasta un tiempo más o menos reciente que esta idea fue cuestionada en su integridad. Así, años después aparecieron reflexiones sugerentes sobre la integración del proletariado europeo al Estado de bienestar o bien ejercicios más frontales en donde se cuestionó sobre el supuesto carácter revolucionario perdido de la clase; o bien si este había existido en alguna en realidad. Revueltas llegó a ellos en la última parte de su vida, pero no en el Ensayo.

Podemos preguntarnos qué implicación tiene ello en la escritura del Ensayo. Desde mi punto de vista el privilegio de la discursividad idealista, con toda su nomenclatura, obnubiló un problema fundamental de la caracterización del Estado mexicano y es que la clase obrera mexicana, el proletariado que protagonizó gran parte de la historia del siglo XX, era un hijo de la revolución. Su nacimiento, crecimiento y 
fortalecimiento en tanto que cuerpo social fue producto del shock modernizante, cuyo centro se encontró en el "milagro mexicano". Dos trayectorias nos permitirían entender esta ambivalencia.

La primera es la del movimiento ferrocarrilero que tuvo su momento de movilización álgida en los años 1958 y 1959. Como se sabe, este fue un episodio crucial en la historia del movimiento obrero, pues demostraba varias cuestiones. La primera era que el proletariado nacido del proceso de modernización era aquel que podía desafiar al dominio corporativo. La segunda, que el desafío de ese dominio corporativo era intolerable para el Estado, pues si se recuerda bien, la afrenta de los ferrocarrileros al régimen no fue otro que la obtención de salario y la posibilidad de la mínima libertad sindical. No es que los ferrocarrileros fueran socialistas o comunistas en cuanto tales, sino que las mínimas demandas representaban algo imposible de ser procesado por el régimen político. La clase obrera había nacido al seno del Estado, éste la cuido y protegido, pero también reprendió cuando mostró signos de rebeldía. El proletariado idealizado del Ensayo se encuentra años luz de las formas específicas de la dominación y del ejercicio de la negociación. Como dijimos al principio, Revueltas miraba con el telescopio de la filosofía de la historia algo que requería el microscopio del análisis de la coyuntura. Se equivoca Rodríguez Kuri (2019) cuando dice que el Ensayo es un texto leninista, pues justamente a Revueltas le hace falta el Lenin que despliega el "análisis concreto de la situación concreta".

La segunda trayectoria es la de la insurgencia sindical de los años setenta, una historia que sin duda habría que volver a mirar con calma y que ha quedado enterrada, debido a la práctica desaparición de estudio del movimiento obrero entre los estudiosos de la historia. La insurgencia sindical (y su corazón, la Tendencia Democrática) de nuevo colocaba una temática: la clase obrera que se movilizaba no era socialista, sino ante todo nacionalista-revolucionaria. Esta perspectiva quedó ausente del planteamiento de Revueltas, pues insistió en la perspectiva del partido-vanguardia encarnación de una conciencia de clase.

\section{En las periferias de la historia}

Si bien es cierto que existen ya avances en la historización del marxismo producido en México (Illades 2018), aún falta reconstruir los momentos de intensidad de debate y combate político. A la visión panorámica le falta la constelación de una multiplicidad de prácticas acontecidas en el espacio/tiempo preciso. Por nuestra parte, hemos querido reconstruir algunos de esos momentos, centrándonos en figuras 
como Carlos Pereyra, Enrique González Rojo y José Revueltas. Se trata de realizar un ejercicio crítico sobre la historia de la corriente intelectual más significativa del siglo XX.

González Rojo, en particular, ejerció las veces de voz crítica de distintos proyectos. Su lectura postalthusseriana logró avanzar en espacios de crítica. En particular su Ensayo sobre las ideas políticas de José Revueltas, logra captar con precisión hasta que punto el Revueltas del Ensayo se encuentra comprometido con lo que en la época se denominaba como "marxismo-leninismo", es decir, con una versión codificada por el Estado soviético de la obra del revolucionario ruso. La renuncia de aquella ideología de poder sólo podía devenir en la abdicación de cualquier idea de un solo partido.

Esta idea, compartida por propios y extraños, tardó en ser abandonada. En el caso del PCM es sugerente leer lo que escribía Martínez Verdugo tras el movimiento estudiantil: "El Partido Comunista no se considera a si mismo el único partido o agrupamiento revolucionario que existe en el país, a pesar de la campaña insidiosa de los que quieren atribuirnos este exclusivo primitivismo" (Martínez Verdugo, 1969: 6). La trayectoria posterior del PCM demostró que esta noción no era sólo un llamado al aire, sino una convicción que devino en la transformación radical tanto del imaginario de la izquierda, como de la propia estructura organizativa. En términos de la producción marxista, años más tarde Carlos Pereyra escribiría sobre la Tendencia Democrática y el papel de las izquierdas: "Si alguna cofradía devota de tal o cual culto tiene la ocurrencia de autodenominarse "vanguardia proletaria" o emplear cualquier otro membrete semejante, ello apenas indica la subjetiva e irrelevante voluntad de unos cuantos, pero si la expresión más madura del movimiento obrero mexicano se define como "tendencia democrática", ello sí revela la dinámica profunda que emerge del suelo mismo de la sociedad" (Pereyra 1990: 128). Con estas frases señalamos como el sendero tomó rutas diversas. El problema no era ya la construcción de el partido, sino el de la democratización. Revueltas fue pionero en la crítica de la ideología de la revolución mexicana y de sus mecanismos de dominio, la construcción del segundo momento - el de la democracia como horizonte necesario para el socialismo- no puede sino considerar ese aporte y encontrar en su producción posterior algunas de las mejores páginas escritas sobre la construcción de ella, desde abajo.

\section{Referencias bibliográficas}

Anguiano A. (2017). José Revueltas, un rebelde melancólico. México: Pensamiento Crítico. 
Aguilar M. (1962). Una teoría de la revolución mexicana. El obrero militante: órgano central de la Liga Obrero Marxista. Número especial. 14-18.

Albiac G. (1977). Al margen de El Capital. Madrid: CUPSA.

Althusser L. (2002). Por un materialismo aleatorio. España: Arena.

(2003). Marx más allá de Marx. Madrid: Akal.

(2004). Crítica previa a la lectura de El Capital. México: Paradigmas y utopías.

(2015). Sobre la reproducción. Madrid: Akal.

(2017). Ser marxista en filosofía. Madrid: Akal.

De la Fuente J (2016). Contra viento y marea: la pertinaz historia del movimiento campesino y la izquierda. México: UACh

Escalante E. (2015). José Revueltas: una literatura del lado moridor. México: FCE.

Fernández L. y Zahonero L. (2010). El orden de El Capital. Madrid: Akal.

(2018). Marx desde cero. Madrid: Akal.

Fuentes Morúa J. (2011). José Revueltas: una biografía intelectual. México: UAM-I.

González Gómez, F. (2017). Recordando a Revueltas. EnVV. AA., Más Revueltas: cinco aproximaciones a la vida de Pepe. México: Brigada para Leer en Libertad.

González Rojo, E. (1962). Por una dirección revolucionaria de la clase obrera. Política: quince días de México y el mundo, (LX), 16-17.

(1987). Ensayo sobre las ideas políticas de José Revueltas. México: Domés.

Illades C. (2018). Historia del marxismo en México. México: Taurus.

Kraniauskas, J. (2016). Políticas literarias. México: FLACSO.

Martínez Verdugo, Arnoldo (1969). El movimiento estudiantil-popular y la táctica de los comunistas. Nueva época (19), 5-15.

Mateo J. (2016). Tiempo de Revueltas. Dos: la discordia proletaria. México: IIF.

Ortega M. (1988). Estado y movimiento ferrocarrilero en México: 1958-1959. México: Quinto Sol.

Pereyra C. (1990). Sobre la democracia. México: Cal y Arena. 
Revueltas J. (1984). Ensayo sobre un proletariado sin cabeza. México: Era.

Rodríguez A. (2019). José ¿radical $\quad$ Revueltas político? [https://www.youtube.com/watch?v=DkxGAO06gEg]

Semo E. (1988). Viaje alrededor de la izquierda. México: Nueva Imagen. 